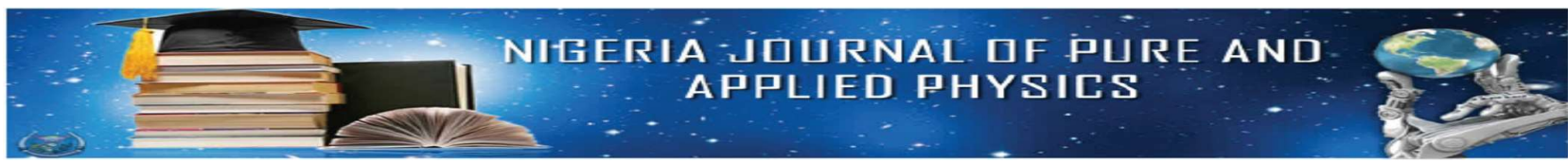

Nigeria Journal of Pure \& Applied Physics, Vol. 8, No. 1, pages 16 - 19 , 2018

\title{
Assessment of Background Radiation Levels in Selected Diagnostic Radiology Department across Ondo State, Nigeria
}

\author{
Oladele B. Blessing and Arogunjo A. Muyiwa \\ Department of Physics, Federal University of Technology, P.M.B 704, Akure. Ondo State, Nigeria. \\ Correspondence email: booladele@futa.edu.ng, blsnoladele44@gmail.com +234-07036830297
}

\begin{abstract}
The indoor and outdoor ionizing radiation exposure levels were measured in some randomly selected radiological laboratories of some hospitals across Ondo State, Nigeria using a Kindenoo PG - 15 Geiger Muller detector. Measurements were taken in each of the radiological laboratories of the hospitals in two phases: first, when the x-ray machines were energized and second, when the x-ray machines were not energized. The mean indoor and outdoor annual effective doses varied from $20.53 \pm 1.07$ to $39.12 \pm 0.09$ and $0.63 \pm 0.32$ to $1.17 \pm 0.45$ $\mathrm{mSv} / \mathrm{y}$ respectively for the first phase in the radiological laboratories and from $1.68 \pm 0.04$ to $2.26 \pm 0.07 \mathrm{and} 0.28 \pm 0.02$ to $0.42 \pm 0.02 \mathrm{mSv} / \mathrm{y}$ respectively for the second phase. Using statistical tools, a post-hoc test was carried out to test for the statistical significant difference between the indoor and outdoor annual effective dose in the study area. The test showed a significant difference between the indoor and outdoor annual effective dose at the radiological laboratories when the $\mathrm{x}$-ray machine was energized and when the $\mathrm{x}$-ray machine was not energized.
\end{abstract}

Keywords: Indoor radiation exposure, Outdoor radiation exposure, X-ray, Annual effective dose

\section{INTRODUCTION}

Many forms of radiation are encountered in the natural environment both originating from natural sources as well as from modern technologies. Of them, ionizing radiation (e.g. X-ray, $\gamma$-ray) has caught the attention of the general public mostly due to the fact that it is widely used in medical diagnosis or therapy and it could damage biological tissues. Exposures from natural sources constitute the largest component of human exposure, although they remain relatively stable over time, contrary to artificial sources of patient, occupational and public exposure (Jibiri, 2001; Stoulos, et al., 2003; Tzortzise, et al., 2004; Ademola and Ogunletu, 2005; Nwanko and Akoshile, 2005; Arogunjo, et al.,2007; Joshua, et al., 2009). The contribution from medical radiation has been the largest among all anthropogenic ionizing radiation (Taskin et al., 2009) and its contribution to the total exposure is increasing. While medical radiation contributes to $20 \%$ of total annual effective dose globaly, it contributes more than $50 \%$ of its share to total annual exposure for US general public (Eugene, 2010).

Most public attention is given to the category of radiation known as ionizing radiation. (Arogunjo et al., 2007). This radiation can disrupt atoms, creating positive ions and negative electrons, and cause biological harm. Ionizing radiation includes x-rays, gamma rays, alpha particles, beta particles, neutrons, and the varieties of cosmic rays. Although people have little control over the kind of radiation to which they are exposed, yet this exposure must be put into perspective. (NCRP, 2005). Ever since radiation was discovered, people have benefited from its uses in the medicine industry and it is the largest source of man-made radiation that people in the industrialized countries are exposed to. (Taskin et al., 2009).

Ionizing radiation is used daily in hospitals and clinics to perform diagnostic imaging procedures. Procedures that use radiation are necessary for accurate diagnosis of disease and injury. These procedures provide important information about our health to the doctor and help ensure that we receive appropriate care. (Lemela et al., 1995). Nevertheless these procedures also have the potential to expose large number of people to radiological hazards especially when the exposure rates are higher when compared to ICRP, 1991 occupational dose limit of 20 $\mathrm{mSv} / \mathrm{y}$. Hence, these therefore indicate that criteria to limit such possibilities should be encouraged. It is therefore necessary to determine the level of ionizing radiation coming from the radiological laboratories when the x-ray machines are energized and when they are not.

Although some researchers have carried out researches on building materials used for the construction of building or dwellings in Nigeria (Ademola, 2008; Jibiri, 2013) but radiological data on exposure rates from radiological laboratories are scare. Consequently, there is a general lack of awareness and knowledge about the level of ionizing radiation to which patients and radiation workers in the radiological laboratories are exposed too. Thus, in this 
work, the indoor and outdoor ionizing radiation level in some randomly selected radiological laboratories were determined both when the x-ray machine was energized and when it was not energized. It was also geared towards determining the associated health hazards posed to the general public in the study area.

\section{2. $0 \quad$ Selection of Sites}

Seven (7) radiological laboratories with x-ray equipment were randomly selected across Ondo State. They are: Federal University of Technology, Akure Health Centre denoted as H1, State Specialist Hospital Akure as H2, General Hospital Ondo as H3, General Hospital Akungba Akoko as H4, General Hospital Ifon as H5, Saint Davids Hospital Akure as H6 and Federal Medical Centre Owo as H7.

\subsection{Measurement}

The instrument used in this radiation survey is a Kindenoo PG-15 Geiger Counter version 38.0 with serial number 0018B2012589. Its measurement range is between 0.05 $\mu \mathrm{Sv} / \mathrm{h}$ and $300 \mu \mathrm{Sv} / \mathrm{h}$ with maximum radiation measurement of $250 \mathrm{mSv}$ and maximum time measurement of 10years. The detector was calibrated at National Institute of Radiation Protection and Research, a secondary standard laboratory certified by International Atomic Energy Agency (IAEA) and a division of the Nigerian Nuclear Regulatory Authority (NNRA). Measurements at each sample point were performed holding the survey meter at 1 $\mathrm{m}$ above sea level. This measurement which is in $\mu \mathrm{Sv} / \mathrm{hr}$ was taken indoor and outdoor respectively when the $\mathrm{x}$-ray machine was energized and when it was not energized.

\subsection{Results}

The indoor annual effective dose (IAED) and the outdoor annual effective dose (OAED) in $m S v y^{-1}$ were calculated using equations given by:

$$
\begin{aligned}
& I A E D\left(m_{S v y}^{-1}\right)=\text { Xmean } \times 8760 h r / y r \times 0.8 \times C F \\
& O A E D\left(m S v y^{-1}\right)=\text { Ymean } \times 8760 h r / y r \times 0.2 \times C F
\end{aligned}
$$

(Jibiri and Sunday; 2013) Where X and Y are the indoor and outdoor dose rates in $\mu \mathrm{Sv} / \mathrm{hr}$ obtained from the Geiger Muller Counter, CF is the conversion factor ( 0.7 for adult), 0.8 and 0.2 are the indoor and outdoor occupancy factors as recommended by UNSCEAR (1988). The results of the study are presented in the figure below. Figure 1 and figure 2 shows the indoor and outdoor annual effective dose of each selected radiological laboratory when the x-ray machine was energized and when it was not energized.

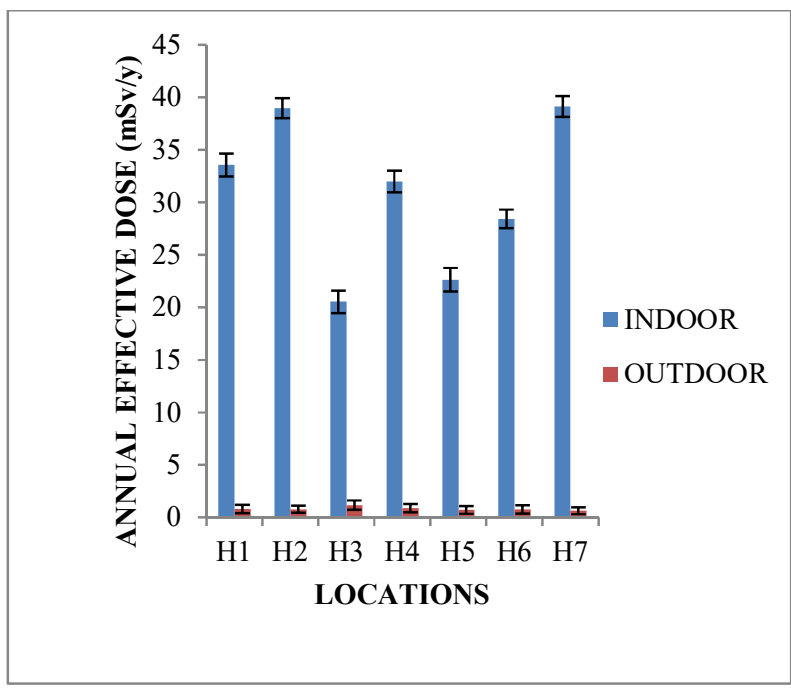

Fig.1. Bar chart illustrating the indoor and outdoor annual effective dose of the selected radiological laboratories when the $\mathrm{x}$ - ray machines were energized

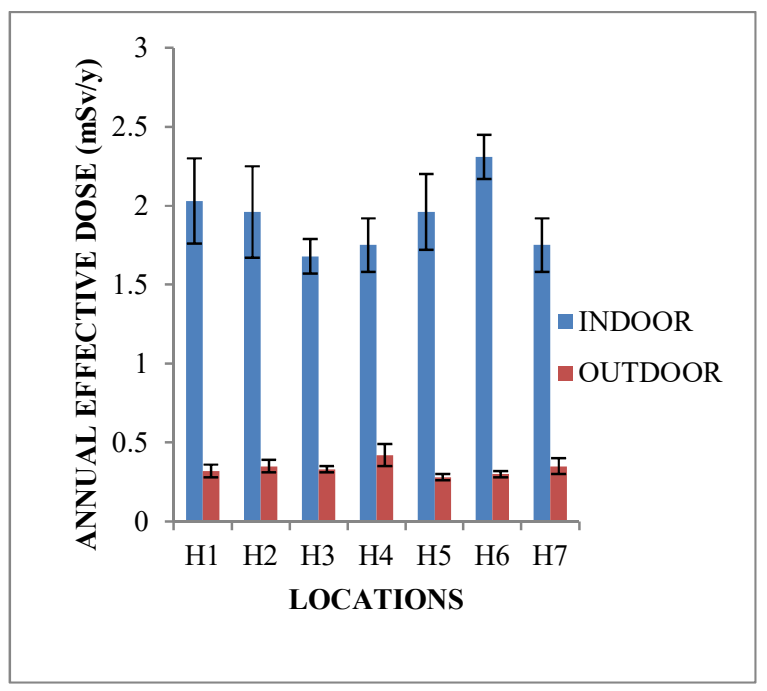

Fig.2.Bar chart illustrating the indoor and outdoor annual effective dose of the selected radiological laboratories when the $\mathrm{x}$ - ray machines were not energized. 


\subsection{Discussion}

Figure 1 above shows the indoor and outdoor annual effective dose in the radiological laboratories when the x-ray machines were energized i.e swiched on. It could be seen that $\mathrm{H} 7$ has the highest level of indoor ionizing radiation with an annual effective dose of $39.12 \mathrm{mSv} / \mathrm{y}$ followed by $\mathrm{H} 2$ and $\mathrm{H} 1$ in that order with an annual effective dose of $38.95 \mathrm{mSv} / \mathrm{y}$ and 33.56 $\mathrm{mSv} / \mathrm{y}$ respectively. The radiation from the $\mathrm{x}$-ray machine when energized was relatively high. X-ray itself been a form of ionizing radiation, hence this level of high indoor radiation at the radiological laboratories/x-ray department in this hospitals could be attributed to the radiations coming from the x-ray machine when its switched on coupled with the radiation coming from other radiation generating devices or machines in the radiological laboratories together with the radiation coming out from the buildings and the building materials used for the construction of the hospitals.

Also the particular place or site where the x-ray machine was situated could be a basement complex (ignite rock) which could also increase the level of ionizing radiation concentration. H3 with an annual effective dose of 1.17 $\mathrm{mSv} / \mathrm{y}$ has the highest outdoor ionizing radiation when the machine is switched on. This could be as a result of the ionizing radiation coming out through the windows and underneath the doors from the radiological laboratory/x-ray room coupled with the background radiation outside. Also leakages from the x-ray machine pipes might have also lead to an increase in the outdoor ionizing radiation. $\mathrm{H} 2$ has the highest indoor annual effective dose of $2.26 \mathrm{mSv} / \mathrm{y}$ when the machine is switched off as seen in figure 2 . This could be attributed to the background radiation in the radiological laboratory and also the radiation coming from the building materials used for the construction of these buildings. $\mathrm{H} 4$ has the highest outdoor annual effective dose rate of $0.42 \mathrm{mSv} / \mathrm{y}$ when the x-ray machine was switched off. This high outdoor ionizing radiation could be attributed to the background radiation in that environment.

The indoor and outdoor annual effective dose when the x-ray machine was energized ranged from $20.53 \mathrm{mSv} / \mathrm{y}$ to 39.12 $\mathrm{mSv} / \mathrm{y}$ and $0.63 \mathrm{mSv} / \mathrm{y}$ to $1.17 \mathrm{mSv} / \mathrm{y}$ while the indoor and outdoor annual effective dose rates when the $\mathrm{x}$-ray machine was not energized ranged from $1.31 \mathrm{mSv} / \mathrm{y}$ to $2.26 \mathrm{mSv} / \mathrm{y}$ and $0.28 \mathrm{mSv} / \mathrm{y}$ to $0.42 \mathrm{mSv} / \mathrm{y}$. These high differences in the level of ionizing radiation when the x-ray machine was energized compared to when it was not energized is as a result of high level of radiation coming from the x-ray machine when it is energized with the addition of the background radiation in the radiological laboratory environment.

\subsection{Tests for Significant Difference}

In this study, a significant ANOVA result was found. In other to know where the significant difference lies, a post - hoc test at $95 \%$ confidence interval was done in this study in other to determine if there is a significant difference between the indoor and outdoor annual effective dose values of the radiological laboratories. After comparing the indoor and outdoor values at the radiological laboratories when the x-ray machine was energized and when it was not energized, the result showed that they are statistically significant different at $\mathrm{p}<0.05$ level because there superscripts are not the same. This clearly shows that we can't use the indoor ionizing radiation annual effective dose in each of the radiological laboratories to predict the outdoor ionizing radiation annual effective dose at each of the radiological laboratories when the $\mathrm{x}$-ray machine was energized and also when it was not energized.

\subsection{Radiological Implication of the Annual Effective Dose Rate and Recommendation}

The linear dose response curve in which the probability of a stochastic effect is proportional to the absorbed dose is assumed in this work. This means that any radiation exposure, no matter how small, involves some degree of risk. Therefore as a result of exposure to high or low dose of ionizing radiation, human are always at risk. The dose received determines the severity of the effect. Examples of these effects are leukemia, tumors, tissue damage, and cataract e.t.c. Some effects won't show immediately but at later years $(10-20$ years $)$. Such as cancer, germline mutations induced by radiation that are transmitted from parents to their offspring. From figure 1 above, it could be seen that the indoor annual effective dose are far higher than ICRP $20 \mathrm{mSv} / \mathrm{y}$ occupational reference limit when the x-ray machine was energized; continuous exposure to these high radiation dose can lead to the effects mentioned above and eventually death. However, all the machines or equipments in the radiological laboratories should be checked and monitored regularly for leakages so as to limit the level of ionizing radiation exposure. Radiation badge must also be worn by the medical personnel's and patients within the hospital laboratories. Routine monitoring should also be carried out at various environments subsequently by the government or the radiation bodies just to monitor the level of ionizing radiation in those radiological laboratories.

\subsection{Conclusion}

The ionizing radiation exposure level in some selected radiological laboratories across Ondo State, Nigeria was carried out in order to determine; the indoor and outdoor ambient ionizing radiation doses in those laboratories, the annual effective dose resulting from exposure to this 
radiation, and then to determine the health hazards posed to the patient and radiation workers. The results showed that only the indoor values were above the internationally accepted ICRP occupational limit of $20 \mathrm{mSv} / \mathrm{y}$ for the general public and radiation workers when the x-ray machine was energized while the outdoor annual effective value falls within the $1 \mathrm{mSv} / \mathrm{y}$ reference limit for the public and radiation workers when the x-ray machine was energized and when it was not energized. This is also an indication that the high level of radiation coming from the x-ray machine when it was energized may have increased the radiation in those areas and may pose significant radiation hazard to the patients and radiation workers at the radiological laboratories and also to occupants in those areas overtime.

\section{References}

Ademola J.A. (2008). Determination of natural radionuclide contents in some building materials in Nigeria by gamma spectroscopy. Health Physics, 94(1); 43-48.

Ademola, J. A. and Oguneletu, P.O. (2005). Radionuclide contents of concrete building blocks and radiation dose rates in some dwellings in Ibadan, Nigeria, Journal of Environmental Radioactivity, 81, 107-117.

Arogunjo A.M. (2007). Tererestrial gamma radiation and the radiological implication in South Western Nigeria . Journal of Applied Sciences. DOI: 10.3923/jas.2007.1534.1537

Arvela, H., H. Hyvönen, H. Lemela et al.((1995) Indoor and outdoor gamma radiation in Finland. Radiat. Prot. Dosim. 59(1): 25-32

ICRP International Commission on Radiological Protection (1991). The 1990- 1991 recommendations of the International Commission on Radiological Protection, Publication 60, Ann. ICRP 21, pp. 1-3.

Jibiri N.N. and Sunday T.U. (2013). Indoor and Outdoor gamma dose rate exposure levels in major commercial building material distribution outlets and their radiological implication to occupants in Ibadan, Nigeria. Journal of Natural Sciences Research; ISSN 2225-0921. Vol 3, No 3.

Jibiri, N.N.(2001). Assessment of health risk levels associated with terrestrial gamma radiation dose rates in Nigeria. Environmental international 27, 21-26.

Joshua, E.O. Ademola, J.A..Akpanowo, M.A. Oyebanjo, O.A .and Olorode, D.O.(2009). Natural radionuclides and hazards of rock samples collected from south eastern Nigeria. Radiation measurements, 44(4), 401-404.

Nwankwo, L.I. and Akoshile, C.O. (2005). Background Radiation Study of Offa industrial area of Kwara state, Nigeria. Journals of Applied science and Environmental management, 9(3), 95-95.

NCRP. National Council on Radiation Protection. (2005). Assessment of background radiation (Annex B). NCRP Report. (National Council on Radiation Protection and Measurements, Bethesda, MD).

Taskin, H., Karavus, M., Ay, P., Topuzoglu, A., Hindiroglum, S., \&Karahan, G. (2009). Radionuclide concentrations in soil and lifetime cancer risk due to gamma radioactivity in Kirklareli, Turkey. Journal of Environmental Radioactivity, 100,49-53.

Tzortzis, M., Svoukis, E., and Tseto, H. (2004). A comprehensive study of natural gamma radioactivity levels and associated dose rates from surface soils in Cyprus. Radiation Protection Dosimetry, 109,.Radiat. Res. 217224

UNSCEAR. 1988. Sources and Effects of Ionizing Radiation, United Nations, New York (1993)

UNSCEAR, 2000. Report to General Assessmbly. Annex B: Exposure from natural radiation sources and report to general assembly with scientific annexes. Vol 1. New York, pp. 1220.

Wikimedia Foundation Inc. (2006). Alpha, Beta, Neuron particles, Gamma rays, X-rays from wikipedia free encyclopedia. www.wikipedia.org/wiki/types-of-ionizingradiation 